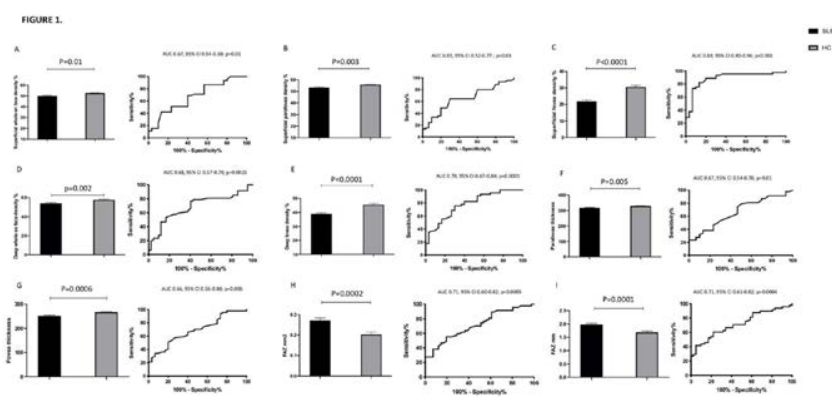

Disclosure of Interests: None declared

DOI: 10.1136/annrheumdis-2021-eular.2637

\section{POS1396 DAMAGE PROGRESSION OF FINGER JOINT CARTILAGE EVALUATED BY ULTRASOUND AND X-RAY IN PATIENTS WITH RHEUMATOID ARTHRITIS (RA)}

T. Ogura ${ }^{1}$, A. Hirata ${ }^{1}$, Y. Inoue ${ }^{1}$, T. Kagtagiri ${ }^{1}$, Y. Takakura ${ }^{1}$, H. Kameda ${ }^{1} .{ }^{1}$ Toho University, Division of Rheumatology, Department of Internal medicine, Tokyo, Japan

Background: Cartilage damage in RA has been evaluated by joint space narrowing (JSN) in X-ray, while it is not a direct evaluation of cartilage. Previously we have confirmed the usefulness of the direct imaging of finger joint cartilage by ultrasound (US) in patients with RA [1].

Objectives: We aimed to examine the temporal changes of US cartilage thickness in RA patients.

Methods: We enrolled 53 RA patients in whom the cartilage thickness of finger joints was measured by US and had radiographs of both hands at baseline and 1 -year later. The cartilage of metacapophalangeal and proximal interphalangeal joints of $2 n d$ to 5 th fingers were bilaterally visualized at the middle portion from a longitudinal dorsal view. Cartilage thickness was measured from the base of the cartilage to the interface artefact at the cartilage surface by static images. In addition, the JSN of the corresponding joints was scored using a hand X-ray by van der Heijde-modified Sharp method. Continuous variables from the two groups were analyzed using the Mann-Whitney $\mathrm{U}$ test or Wilcoxon signed-rank test. The relationships among the continuous variables were assessed using the Spearman's rank correlation coefficient.

Results: The median age of the patients was 68 years and the median disease duration was 6.3 years. The sum of total cartilage thickness from 16 joints per patient ranged from 3.1 to $9.1 \mathrm{~mm}$ (median $6.5 \mathrm{~mm}$ ) at baseline, and it was significantly correlated with total JSN score of the same joints $(\rho=-$ $0.63, p<0.001)$. The cartilage thickness was inversely correlated with disease duration (rho $=-0.40, p=0.003$ ), but not associated with age nor height. The decrease in cartilage thickness over 1 year was evident in patients with persistent moderate to high disease activity by the DAS28-CRP ( $n=10$; median
$-6.2 \%)$ as compared with other patients $(n=43$; median $-1.2 \%, p=0.004$ versus active patients)

Conclusion: This pilot study demonstrated the progression of cartilage damage by sustained RA activity, supporting the validity and usefulness of joint cartilage thickness evaluation by ultrasound in patients with RA.

REFERENCES:

[1] Ogura T, et al. Arthritis Care Res 2019 Oct 25.

Disclosure of Interests: None declared

DOI: 10.1136/annrheumdis-2021-eular.2784

\section{POS1397 HYDROXYCHLOROQUINE INDUCED RETINAL TOXICITY IN PATIENTS WITH RHEUMATIC DISEASES}

R. Maheshwari ${ }^{1}$, R. Sankaralingam2, S. Chinnadurai2, J. Antony2,

B. Chilukuri2, M. Mani2. ' Sri Ramachandra Institute of Higher Education and Research, Clinical Immunology and Rheumatology, Chennai, India;

${ }^{1}$ Sri Ramachandra Institute of Higher Education and Research, Clinical Immunology and Rheumatology, Chennai, India

Background: Retinal toxicity from hydroxychloroquine (HCQ) is rare, but the vision loss maybe irreversible and could have medicolegal consequences. Objectives: To determine the prevalence and assess the predictors of retinal toxicity due to $\mathrm{HCQ}$ in patients with rheumatic diseases. There is paucity of literature on retinal toxicity due to $\mathrm{HCQ}$ in rheumatic diseases.

Methods: A retrospective observational study was conducted in the Department of Clinical Immnuology and Rheumatology, Sri Ramachandra Institute of Higher Education and Research,Chennai, India from November 2018-May 2020, on patients taking $\mathrm{HCQ}$ for more than 6 months. All patients underwent ophthalmological screening at baseline and every 6 months, and thereafter by modern day screening methods-Humphrey Visual Field (HVF)10-2, Spectral Domain Optical Coherence Tomography(SD-OCT), except for patients with evidence of suspected retinal toxicity at baseline.Fundus autofluorescence (FAF) was done in feasible patients.

Results: 9 out of $743(1.2 \%)$ patients were identified to have retinal toxicity, detected via fundus examination ( $n=9)$, SD-OCT $(n=8 / 9)$, HVF 10-2 $(n=6 / 9)$, FAF $(n=1 / 9) .55 .5 \%(n=5 / 9)$ had Rheumatoid Arthritis(RA) and $44.4 \%(n=4 / 9)$ had Systemic Lupus Erythematosus(SLE) as their primary diagnosis. $77.7 \%(n=7 / 9)$ were females. The mean age was 47.5 years (20-72 years). $75 \%(n=3 / 4)$ of SLE patients were below 30 years of age. The average daily and cumulative dose of $\mathrm{HCQ}$ in these 9 patients were $244 \mathrm{mg}(200-400 \mathrm{mg})$ and $311.22 \mathrm{~g}(73-730 \mathrm{~g})$ respectively, whereas the mean recommended dose as per real body weight was $287.2 \mathrm{mg} /$ day. Average duration of HCQ consumption was 3.6 years (1-10 years). Only $11.1 \%(n=1 / 9)$ had presented with visual complaints of black floaters.

Conclusion: The asymptomatic nature of this irreversible toxicity, warrants frequent screening.Retinal toxicity was not age-related.Toxicity was manifested at low daily and cumulative doses.Screening should be done atleast every 6 months by fundus examination.Objective tests like HVF and SD-OCT should be done annually, especially in patients with underlying rheumatic diseases. The early manifestation of retinal toxicity in young SLE patients could have a genetic association and needs further evaluation.

Table 1. SALIENT FEATURES OF THE 9 PATIENTS PRESENTING WITH RETINAL TOXICITY DUE TO HCO

\begin{tabular}{|c|c|c|c|c|c|c|c|c|c|c|c|c|}
\hline \multirow[b]{2}{*}{$\begin{array}{l}\text { Sl. } \\
\text { No }\end{array}$} & \multirow[b]{2}{*}{ Age } & \multirow[b]{2}{*}{ Gender } & \multirow[b]{2}{*}{$\begin{array}{l}\text { Weight } \\
(\mathrm{Kg})\end{array}$} & \multirow[b]{2}{*}{$\begin{array}{l}\text { Primary } \\
\text { Diagnosis }\end{array}$} & \multicolumn{3}{|l|}{ Dose } & \multirow[b]{2}{*}{$\begin{array}{l}\text { Duration } \\
\text { (Years) }\end{array}$} & \multicolumn{4}{|l|}{ Detection Method Used } \\
\hline & & & & & $\begin{array}{l}\text { Recommended } \\
\text { Dose } \\
\text { (mg/Day) }\end{array}$ & $\begin{array}{l}\text { Received } \\
\text { Dose } \\
\text { (mg/Day) }\end{array}$ & $\begin{array}{l}\text { Cumulative } \\
\text { Dose } \\
\text { (grams) }\end{array}$ & & $\begin{array}{l}\text { FUNDUS } \\
\text { EXAM. }\end{array}$ & SD-OCT & $\begin{array}{l}\text { HVF } \\
10-2\end{array}$ & $\begin{array}{l}\mathrm{F} \\
\mathrm{AF}\end{array}$ \\
\hline 1 & 47 & $\mathrm{~F}$ & 58 & SLE & 290 & 400 & 438 & 3 & RPE Changes & Thinning/Photoreceptor Loss & Defects seen & - \\
\hline 2 & 20 & $\mathrm{~F}$ & 46 & SLE & 230 & 200 & 146 & 2 & $\begin{array}{l}\text { Multiple Small Drusens In } \\
\text { Paramacular Area }\end{array}$ & $\begin{array}{l}\text { Multiple } \\
\text { Drusens }\end{array}$ & Normal & $\begin{array}{l}\text { Perifoveal autofluo- } \\
\text { rescence spots- } \\
\text { drusens }\end{array}$ \\
\hline 3 & 23 & $\mathrm{~F}$ & 50 & SLE & 250 & 400 & 146 & 1 & RPE Changes & $\begin{array}{l}\text { RPE } \\
\text { Disruptions }\end{array}$ & Defects seen & - \\
\hline 4 & 30 & $\mathrm{~F}$ & 55 & SLE & 275 & 200 & 73 & 1 & Normal & Normal & Paracentral Scotoma & - \\
\hline 5 & 50 & $\mathrm{~F}$ & 49 & RA & 245 & 200 & 511 & 7 & $\begin{array}{r}\text { Early Bull's Eye } \\
\text { Maculopathy }\end{array}$ & $\begin{array}{l}\text { RPE } \\
\text { Atrophy }\end{array}$ & Defects seen & - \\
\hline 6 & 72 & $\mathrm{~F}$ & 60 & RA & 300 & 200 & 730 & 10 & $\begin{array}{l}\text { RPE Atrophy } \\
\text { FR Absent }\end{array}$ & $\begin{array}{l}\text { RPE } \\
\text { Atrophy }\end{array}$ & $\begin{array}{l}\text { General reduction in } \\
\text { sensitivity }\end{array}$ & - \\
\hline 7 & 65 & M & 57.4 & $\mathrm{RA}$ & 287 & 200 & 146 & 2 & RPE Changes & $\begin{array}{l}\text { RPE } \\
\text { Disruptions \& Thinning Noted }\end{array}$ & Defects seen & - \\
\hline 8 & 62 & $\mathrm{~F}$ & 70 & $\mathrm{RA}$ & 350 & 200 & 219 & 3 & Chorioretinal Atrophy & $\begin{array}{l}\text { Altered } \\
\text { RPE } \\
\text { Membrane }\end{array}$ & Defects seen & - \\
\hline 9 & 59 & M & 71.6 & $\mathrm{RA}$ & 358 & 200 & 292 & 4 & RPE Changes & $\begin{array}{l}\text { RPE } \\
\text { Disruptions }\end{array}$ & Normal & - \\
\hline
\end{tabular}

F:Female; M:Male; SLE:Systemic Lupus Erythematosus; RA: Rheumatoid Arthritis, FUNDUS EXAM.: Fundus Examination; SD-OCT:Spectral Domain-Optical Coherence Tomography, HVF 10-2:Humphrey Visual Field 10-2; FAF: Fundus Autofluorescence, RPE:Retinal Pigment Epithelium; FR:Foveal Reflex 